\title{
Characterization and Utilization of Rice Husk Ash (RHA) from Rice Mill of Bangladesh
}

\author{
K. N. Farooque ${ }^{\mathrm{a} *}$, M. Zaman ${ }^{\mathrm{a}}$, E. Halim ${ }^{\mathrm{b}}$, S. Islam ${ }^{\mathrm{a}}$, M. Hossain ${ }^{\mathrm{a}}$, Y. A. Mollah ${ }^{\mathrm{b}}$ and A. J. Mahmood . \\ ${ }^{a}$ IGCRT, BCSIR Laboratories, Dhanmondi, Dhaka-1205 and ${ }^{b}$ Department of Chemistry, \\ University of Dhaka, Dhaka-1000, Bangladesh.
}

\begin{abstract}
The characterization of Rice Husk Ash (RHA) was carried out using conventional chemical analysis and instrumental techniques. Chemical analysis reveals that RHA contains mainly silica along with minor inorganic oxides. Phase analysis by X-ray diffraction (XRD) indicates the presence of quartz, crystobalite and anorthite, while micro structural features obtained from Scanning Electron Microscopy (SEM) shows that RHA particles are highly porous and honeycombed structure. Thermal analysis indicates the presence of surface moisture. A wide range of particles (0.001-0.100 mm) are present in the sample with 59\% below the size of $0.05 \mathrm{~mm}$. However after characterization, utilization of RHA as a potential cost effective ingredient in developing a variety of construction materials (e.g. building brick, insulating brick and pozzolana cement) have been examined. The results obtained are very promising.
\end{abstract}

Keywords : Charcterization, Rice husk ash, XRD, SEM, Construction material.

\section{Introduction}

Rice husk (RH) is an agricultural waste. In Bangladesh, about 39.3 million ton of rice is produced annually (Mustafi, 2005) which generate about 9.83 million ton of RH after milling of the paddy. The RH is generally used as fuel in rural areas and a small quantity is used as animal feed. Huge quantity of rice husk ash (RHA) is generated in Bangladesh during per-boiling of rice in rice mills. This ash is treated as a waste material usually dumped at the backyard causing unforeseen environmental hazards. No systematic efforts have yet been made for exploitation of this replenishible major agricultural by-product on commercial basis due to lack of detailed characterization of the RHA produced in Bangladesh.

RHA is predominantly silica together with some minor oxides (Agarwal, 1989, Kumar, 1993). The nature of this silica depends on the burning temperature. Controlled combustion of RH produces reactive silica (Agarwal, 1989, Kumar, 1993, Ibrahim, and Helmy 1981) which is suitable for making pozzolana cement (Kumar, 1993). It is reported (Agarwal, 1989) that silica present in RHA remains amorphous up to $973 \mathrm{~K}$. With further increase in temperature, crystallization of silica occurs. Techniques for burning RH to produce amorphous silica, which is suitable for pozzolana cement production, have been developed (Kumar, 1993,

\footnotetext{
*Corresponding Author, Email:ysom2002@yahoo.com
}

Ahmed, et al.1993). Nehdi et al. (2003) have developed a new technique for complete combustion of Egyptian RH to make it suitable for construction industry. A mini incinerator has been designed by Ahmed, et al.(1993) in BCSIR laboratory, Dhaka to produce RHA and a comparative study has been carried out in relation to compressive strength and setting time of the pozzolana cement prepared by using this ash and boiler ash.

Characterization of RHA by SiMAS NMR, XRD and FESEM has been investigated by Harridan et al. (1997) for synthesis of zeolites. Borthakur et al. (1980) have reported thermal and infrared spectra of RHA prepared at different temperatures. SEM images have indicated (Zhang et al., 1996) that the ash is a highly porous and fibrous material with high surface area and honeycombed microstructure. Scanning Force Microscope has been used for the surface characterization of calcined $\mathrm{RH}$ and it is reported that the surface roughness of RHA is decreased while the number of voids is increased with the increase of temperature (Vempati et al., 1995).

The primary objective of the present study is to characterize the RHA collected from rice mill to evaluate its suitability as a building material such as pozzolana cement, composite 
cement, building brick, tiles and insulating brick. A number of methods that include chemical analysis, X-ray diffraction, DTA/TGA, particle size analysis, SEM have been used in this study.

\section{Materials and Methods}

\section{Materials}

RHA was collected from rice milling area of Munshigonj and was finely ground in a pulverizer

\section{Chemical analysis of RHA}

Chemical characterization of RHA was carried out using classical methods as well as by instrumental techniques like PFP7 JENWAY (UK) flame photometer and UV-2201 SHIMADZU (Japan) UV spectrophotometer.

\section{Particle size distribution}

Particle size was determined by sedimentation and sieve analysis using a density hydrometer and various sizes of sieve respectively. The method was based on Stroke's law (Bowles, 1992).

\section{XRD analysis}

The phase composition of the RHA was determined by the XRD analysis of the sample with Philips X-ray Diffiactometer model operating with a $\mathrm{CuK} \alpha$ radiation source $\left(\mathrm{K} \alpha=1.5406 \mathrm{~A}^{\mathrm{O}}\right)$. The samples were ground to a fine powder and loaded on a silicon low background sample holder over baseline adhesive. The XRD scans were recorded from $10-80^{\circ} 2 \theta$ with $0.20^{\circ}$ step-width and 5.1 s counting time for every step. Phase analysis was performed by comparing the $d$ values and intensity ratios of the main fundamental peaks with data available in the data book published by the Joint Committee of Powder Diffraction Standards (1974).

\section{SEM analyses}

Morphological examination of the RHA was carried out on a 2600SN Hitachi (Japan) Scanning Electron Microscope (SEM) equipped with Germanium detector and Diamond window. The samples were mounted using double-sided tape.

\section{DTA/TGA analysis}

DTA/TGA Labsys ${ }^{\mathrm{TM}}$ from SETARAM was used to evaluate the thermal behaviors of the sample. The heating rate for DTA/TGA analysis was $10^{\circ} \mathrm{C} / \mathrm{min}$. The temperature difference between an inert (Alumina) and the sample was record- ed and mass loss was calculated from the TG curve.

\section{Preparation of building brick and its characterization:}

Building brick was made from RHA - Soil mixtures (RHA: Soil $=70: 30,80: 20$ and $90: 10$ ) which was ball milled. The optimum water for making the batch composition in workable condition increases as the quantity of rice husk ash was increased. 2 ' ' cube specimens were prepared by applying a pressure of $60 \mathrm{~kg} / \mathrm{cm}^{2}$. Specimens were released from the mold, dried at $110^{\circ} \mathrm{C}$ and fired at $1100^{\circ} \mathrm{C}$. Water absorption, bulk density (ASTM C 830-00 method) and cold crushing strength (CCS, ASTM C 109 method) were determined.

Linear shrinkage was also determined by preparing rectangular bar (10 x I.5 x $\left.0.6 \mathrm{~cm}^{3}\right)$ from control (100\% soil) and RHA - soil mixtures (100:0, $90: 10,80: 20$ and $70: 30)$. The test sample was mixed with optimum water just to moisten it and placed in a mold and pressed by applying a pressure of 10 ton on the surface and a straight line was drawn on the surface of the test specimen. The sample was dried at $110^{\circ} \mathrm{C}$ followed by firing at $1000^{\circ} \mathrm{C}$ in an electric muffle furnace. The difference in the linear change indicates the linear shrinkage.

Insulating brick was prepared by taking RHA (coarse) to soil in the ratio of $70: 30$ and either $\mathrm{CaO}(5 \%)$ or sodium silicate (5\%). The RHA and soil were mixed properly but not ball milled as coarser grain being required for thermal insulation. Except applying 3t pressure, preparation of test specimen follows the same procedure that was used for making building brick. The bulk density (\%), \% apparent porosity and CCS of the products were determined.

Pozzolanic cement was produced from RHA and lime at different ratios and ball milled for $3 \mathrm{~h}$. The cement was then kept in airtight container. CCS measurements were carried out at a definite interval following ASTM C 109 method. The physico-chemical properties of the soil used were also evaluated (Farooque et al., 2005)

\section{Results and Discussion}

\section{Compositional analysis}

The composition of the RHA sample has been determined by chemical analyses. The RHA used in this study contains: $\mathrm{SiO}_{2}$ (91.3\%), $\mathrm{Al}_{2} \mathrm{O}_{3}$ (0.3\%), $\mathrm{Fe}_{2} \mathrm{O}_{3}$ (0.12\%), $\mathrm{CaO}$ (0.21\%), $\mathrm{MgO}$ (0.31\%), $\mathrm{Na}_{2} \mathrm{O}$ (1.52\%), $\mathrm{K}_{2} \mathrm{O}$ (2.65\%), $\mathrm{TiO}_{2}$ (0.15\%), $\mathrm{SO}_{3}(0.24 \%)$ and it undergoes $2.7 \%$ weight loss on ignition. It is evident that RHA contains mainly silica. A survey of literature (Kumar et al., 1989, Al-Khalaf et al., 1984) reveals that usually $79.5-97.6 \%$ silica is found in RHA and $90 \%$ of 
this silica is present in gel form and the remaining is in the form of metallic silicates or in fine colloidal form. Presence of small quantities of $\mathrm{K}_{2} \mathrm{O}=2.65 \%$ and $\mathrm{Na}_{2} \mathrm{O}=1.52 \%$ (Qijun et al., 1999, Sing et al., 2001) in RHA makes it suitable raw material for producing composite cement. The loss on ignition indicates that small amount of free carbon is retained in RHA due to insufficient asking of the husk.

\section{Particle size distribution}

Particle size analysis of RHA (Fig. 1) shows that $~ 8 \%$, $\sim 41 \%, \sim 8 \%$, and $\sim 10 \%$ of RHA particles are in the range of 0.1 - $0.05 \mathrm{~mm}, 0.05$ - $0.01 \mathrm{~mm}, 0.01-0.005 \mathrm{~mm}, 0.005$ $0.001 \mathrm{~mm}$ respectively. According to ASTM C 593 - 66 T standard the particle size of RHA when wet sieved should retain $20 \%$ on $0.045 \mathrm{~mm}$ sieve for composite cement/pozzolana cement production. The present result indicates that $59 \%$ of RHA particles are below $0.05 \mathrm{~mm}$. Therefore, it is suggested that further grinding is required to obtain the required particle size, of RHA for the production of composite/pozzolana cement by utilizing RHA from rice mill.

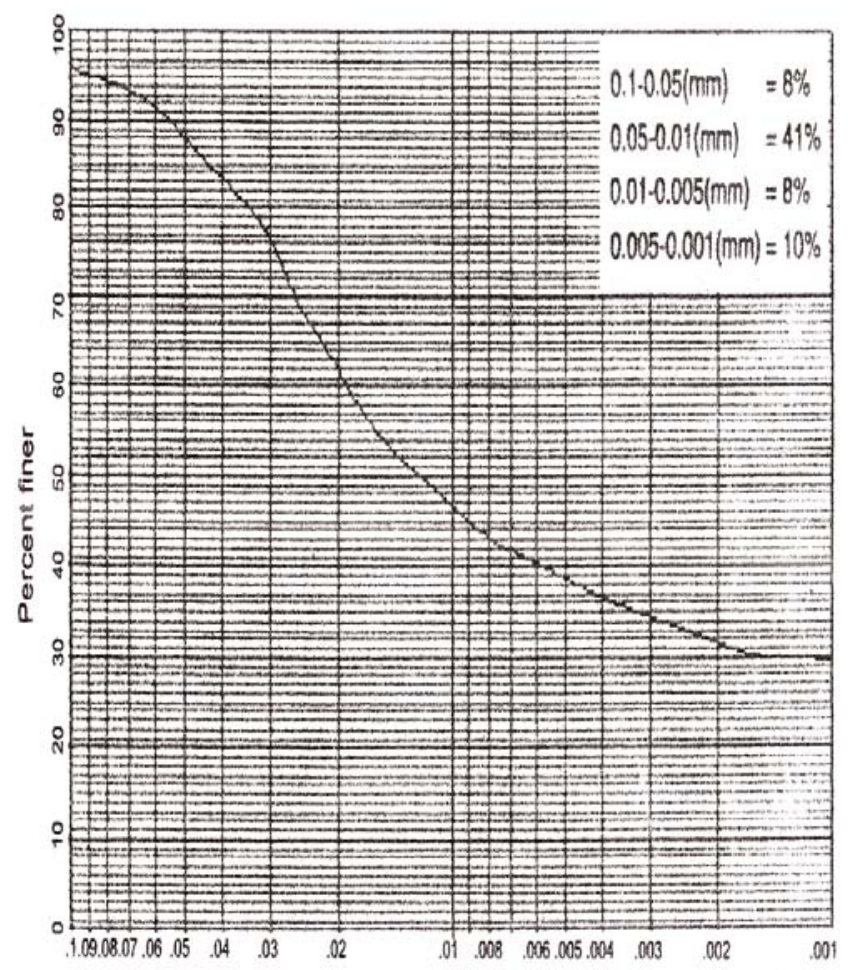

Grain diameter, mm

Fig.1 : Particle size distribution of RHA

\section{Phase analysis:}

The XRD pattern of RHA (Fig. 2) indicates the presence of quartz $\left(22.85^{\mathrm{O}}, 26.63^{\mathrm{O}}\right.$ and $42.47^{\mathrm{O}} 2 \theta$ peaks) and crystobalite $\left(21.91^{\mathrm{O}}, 35.99^{\mathrm{O}}\right.$ and $69.50^{\mathrm{O}} 2 \theta$ peaks). Anorthite

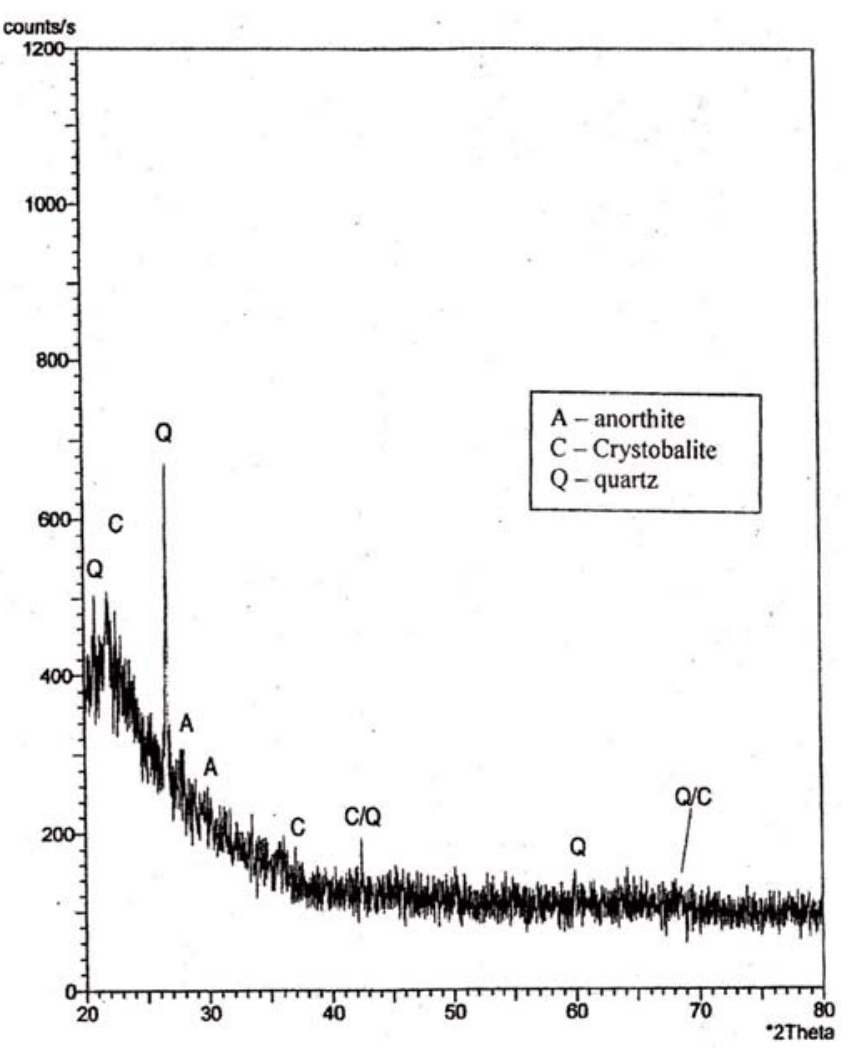

Fig.2 : X-ray diffraction of RHA

phase is also found $\left(27.91^{\mathrm{O}}\right.$ and $29.42^{\mathrm{O}} 2 \theta$ peaks). It has been reported (Agarwal, 1989) that at low temperature (873 - $973 \mathrm{~K}$ ) silica in RHA is amorphous, and crystallization occurs when temperature goes above $973 \mathrm{~K}$ (Agarwal, 1989). The presence of crystobalite phase indicates that RHA is produced above $973 \mathrm{~K}$. At high temperature, quartz is transformed to tridymite (Metha et al., 1976) which is favored in presence of impurities in RHA (Metha and Pith 1974).

\section{Morphological analysis}

A typical SEM image of RHA is presented in Fig. 3. The SEM photomicrograph reveals the siliceous nature of the ash, which is also confirmed by the presence of quartz in the XRD. Close examination of the SEM photomicrograph also suggests that RHA is highly porous which is in agreement with others (Zhang and Malhotra 1996). The porous nature 
of RHA and its honeycombed structure is responsible for its high specific surface and makes it suitable for making insulating brick.

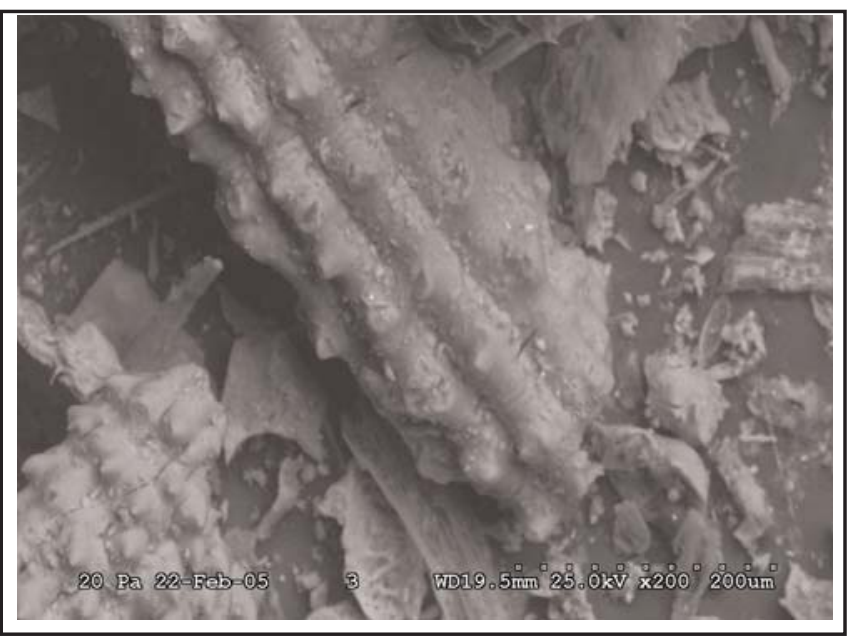

Fig. 3 : Microstructure of RHA

\section{Thermal analysis}

The thermal analysis curve (DTA) of RHA is presented in Fig.4. The endotherm starting from room temperature to around $423 \mathrm{~K}$ is accompanied by weight change in TG curve. The endothermic peak corresponding to around $373 \mathrm{~K}$ can be attributed to elimination of surface moisture. The endotherm is followed by a broad and diffused exotherm in the temperature region 623 - $873 \mathrm{~K}$ which has also been observed by Borthakur et al., (1980). No other change such as structural transformation or formation of new compounds has been

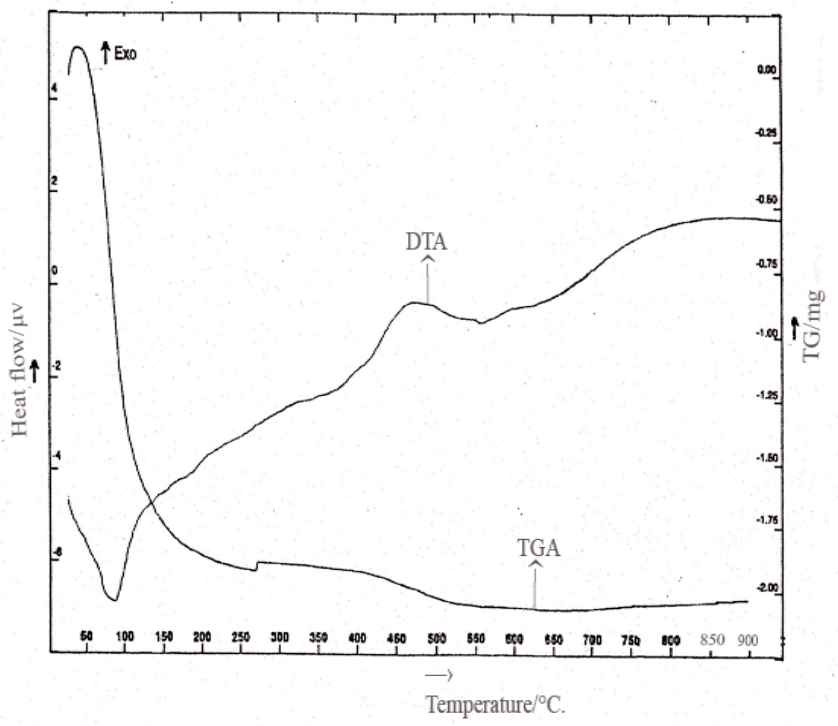

Fig. 4 : DTA/TGA Curves of RHA observed with the increase in temperature. The shifting of baseline of thermogram at higher temperature is possibly due to change of surface properties of silica present in RHA (Borthakur et al.,1980).

The properties of brick specimens produced from a mixture of rice husk ash and red soil (Mirpur) in different proportion are shown in Table (I). As the proportion of RHA increases a gradual decrease in strength and bulk density whereas, an increase in water absorption are observed. The main reason may be due to the presence of unburnt carbon, which makes the specimen porous on firing at high temperature. Another cause may be the increase in optimum water content when quantity of rice husk ash increases. This is in good agreement with the study carried out by Hajela and Gupta (1997).

Table I. Physical property of RHA - Soil brick.

\begin{tabular}{c|c|c|c|c|c}
\hline $\begin{array}{c}\text { Soil, } \\
(\%)\end{array}$ & $\begin{array}{c}\text { RHA, } \\
(\%)\end{array}$ & $\begin{array}{c}\text { CCS, } \\
\text { Psi }\end{array}$ & $\begin{array}{c}\text { Water } \\
\text { absorption, }\end{array}$ & $\begin{array}{c}\text { Bulk } \\
\text { density, }\end{array}$ & $\begin{array}{c}\text { Linear } \\
\text { shrinkage }\end{array}$ \\
\hline Control & 0 & 2600 & 15.0 & 1.78 & 9.8 \\
90 & 10 & 2020 & 15.45 & 1.74 & 8.3 \\
80 & 20 & 1850 & 20.45 & 1.70 & 7.6 \\
70 & 30 & 1700 & 22.15 & 1.53 & 7.4 \\
\hline
\end{tabular}

Rahman (1988) has observed increase in compressive strength with increase in \% RHA. In fact, increase or decrease in compressive strength as well as other properties depend on the type of soil, type of kiln and also manufacturing process. As Bangladesh Standard Specification for common clay brick requires compressive strength of 2000 psi for Grade B and Grade C brick, respectively and water absorption from 12-16\% for B and C Grade brick, therefore 10\% RHA can safely be used for the production of building brick for wall construction. It is also observed that percent linear shrinkage of RHA - soil mixture (Table I) decreases as the quantity of RHA increases. According to Hazela and Gupta (1997) and Sabrah et al. (1989) the linear shrinkage decreases with the increase of RHA used for brick making. This is very advantageous for the production of tile as shrinkage can deform the article during firing. Controlling of shrinkage on firing is an important criterion in manufacturing tile. The burnt specimens for brick and tile show brick red color, which is the primary requirement of the consumer.

Chemical analysis of RHA shows that it contains some unburnt carbon, which is required for thermal insulation. The presence of oxides also favours the formation of vitreous phases during sintering of the insulating brick. The effect of additive ( $\mathrm{CaO}$ or sodium silicate) on the properties of insulating brick is shown in Table II. It shows that thermal insu 
Table II. Physical property of insulating brick (RHA: Clay $=70: 30)$.

\begin{tabular}{c|c|c|c}
\hline Additive & $\begin{array}{c}\text { Apparent } \\
\text { porosity (\%) }\end{array}$ & $\begin{array}{c}\text { Bulk density } \\
\text { (gm/cc) }\end{array}$ & $\begin{array}{c}\text { CCs } \\
\text { psi }\end{array}$ \\
\hline $\mathrm{CaO}$ & 0.68 & 0.73 & 350 \\
Sodium & 0.61 & 0.85 & 680 \\
Silicate & & & \\
\hline
\end{tabular}

lating specimens have low bulk density, as a consequence of high porosity.

Change in \% of apparent porosity, bulk density and CCS have been observed for the two types of additive. CaO bonded insulating brick achieve lower compressive strength compared to sodium silicate bonded brick as also observed by Kapur (1980). Consequently \%AP is more and BD is less for $\mathrm{CaO}$ bonded brick than for the sodium silicate bonded brick. This has also been observed by Kapur (1980). The presence of unburnt carbon, oxide as well as coarse particles makes the RHA potentially suitable to be used as a raw material for thermal insulating brick.

\section{Ash-Lime Composite Cements}

The CCS of RHA - Lime Composite Cement has been measured at different Ash-Lime ratios for 90 days. The primary objective of this experiment is to determine the optimum ratio of Ash-Lime that can impart maximum strength.

Table III indicates that RHA-Lime ratio of 2:1 achieves better strength compared to RHA - Lime ratios of 1:1 and 1:2. However, various Ash-Lime ratios have been reported (James et al., 1992) as optimum for developing maximum strength and widely varying strength. Recent study of Nair

Table III. Compressive strength of RHA - Lime composite cement.

\begin{tabular}{c|c|c|c}
\hline \multirow{2}{*}{ Ageing } & \multicolumn{3}{|c}{ Compressive strength, psi } \\
\cline { 2 - 4 } & RHA: Lime=2:1 & RHA: Lime=1:1 & RHA: Lime=1:2 \\
\hline 7 & 550 & 525 & 350 \\
28 & 800 & 650 & 600 \\
90 & 1000 & 800 & 750 \\
\hline
\end{tabular}

et al., (2006) indicates that unburnt carbon can adversely affect the strength.

\section{Conclusions}

The results of characterization of RHA confirm that silica is the major oxide present in RHA and the two most important phases are quartz and crystobalite. About 59\% of RHA particles are below $0.05 \%$ mm size which implies that RHA particles need further grinding to make it suitable for pozzolanic cement. The particles are porous and irregular that makes it a suitable material for producing insulating brick. The thermogram and weight loss curve of RHA particles show the presence of surface moisture.

The addition of 10\% RHA produces brick, which conform to Bangladesh Standard Grade C, which can be used in wall construction. Using a simple technology it is possible to manufacture low cost thermal insulating brick from RHA for dryers, ovens, furnaces. Clay roofing tiles can also be produced from RHA.

\section{References}

Agrawal B. M. (1989). Utilization of rice husk ash, Glass Ceram. Bull., 36: 1-2.

Al-Khalaf M. N., and Yousif H. A. (1984) Use of rice husk ash in concrete. Int. J. Chem. Comp. Light Wt. Conc., 6 (4): 241-248.

Ahmed S., Hossain M. I., and Farooque K. N. (1993) Studies on rice husk ash cement. Bang. J. Sci. Ind. Res., 28(2):71

Borthakur P. C., Saikia P. C., and Dutta S. N. (1980) physicochemical characteristics of silica from paddy husk, its reactivity and probable field of application, Ind. Ceram. 23(2): 25-29

Bowles E. J. (1992) Engineering Properties of Soils and Their Measurement, 2nd Ed. McGrwHill Int. Book Co. Newyork.USA, pp.13-16.

Farooque K. N., Zaman M., Rahman A., and Halim M. E. (2005) Studies on the suitability of soil for making soil stabilized building block, Bang. J. Sc. Ind. Res., 40(1-2): 9-18.

Hamdan H., Muhid M. N. M., Endud S., Listiorini E., and Ramli Z. (1997) 29Silica MAS NMR, XRD and FESEM studies of rice husk ash silica for the synthesis of zeolites, J. Non-crystal. Solid, 211: 126-131.

Hajela R. B., and Gupta R. G. (1997). Rice husk utilization in brick and tile manufacturing, Energy Management: Quart. J. Nat. Prod. Coun. CGCRI, Kolkata, India., 21(2): 9-16.

Ibrahim D. M., and Helmy M. (1981) Crystalline growth of rice husk ash, Thermochim. Acta., 45: 79-85. 
Jose J., and Subbarao M. (1992) Reactivity of silica from rice husk with lime, J. Can. Ceram. Soc., 2: 61.

Kumar A., Das D. K., and Banerjee G. (1989). Internal report on utilization of rice husk ash for cost effective building materials, CGCRI, Kolkata, India, pp.113

Kumar A. (1993) Rice husk ash based cements, mineral admixture in cement and concrete, progress in cement and concrete, Ed. Ghosh, S. N. Sarker S. L. and Harsh, S. ABI Books Pvt. Ltd. CGCRI, Kolkata, India, 4:342367

Kapur P. C. (1980) Thermal insulations from rice husk ash, an agricultural waste, Ceram. Int., 2: 6.

Metha P. K., and Pitt N. (1974). 4th Int.Conf. of rice byproducts utilization, Valencia.Spain., 4(1): 494

Metha P. K., and Pitt N. (1976). Energy and industrial materials from crop residues, Res. Recov. Conserv., 2(1): 2338.

Mustafi B. A. A. (2005) Statistical Yearbook of Bangladesh Bureau of Statistics (BBS).

Nehdi M., Duquette J., and Damatty A. E. (2003) Performance of rice husk ash produced using a new technology as a mineral admixture in concrete, Cem. Concr. Res., 33: $1203-1210$

Nair D. G., Jagadish K. S., and Fraaij A. (June 2006) Reactive pozzolanas from rice husk ash: an alternative to cement for rural housing Cem. Concr. Res., 36(6): 1062-1071.
Qijun Y., Sawayama K., Sujita S., Shoya M., and Isojima Y. (1999) The reaction between rice husk ash and $\mathrm{Ca}(\mathrm{OH}) 2$ solution and the nature of its product Cem. Concr. Res., 29: 37-43.

Rahman M. A. (1988) Effect of rice husk ash on the properties of brick from fired lateritic soil clay mixture, Mat. Struc., 3: 21.

Sabrah B. A., Didamony H. E. I., and Rabiehi M. M. E I. (1989) Ceramic studies of the clay/ricehusk/slug system and stability for brick making. Utilization of some agro-industrial waste in the treatment of expanded clays to be suitable in the brick making. Prepared as a paper to the sci. ceram. Cong. Orleans, France., 13: 9 - 11

Sing N. B., and Rai S. (2001) Effect of PVA on the hydration of cement with rice husk ash, Cem. Concr. Res., 31: 239-243.

Joint Committee of Powder Diffraction Standards (1974) Selected Powder Diffraction Data for Mineral.1st Ed.USA. pp-851.

Vempati R. K., Musthyala S. C., Mollah. M. Y. A., and Cocke, D.L. (1995) Surface analyses of pyrolysed rice husk using scanning force microscopy, Fuel., 74(11): 1722-1725.

Zhang M. H., and Malhotra V. M. (1996) High performance concrete incorporating rice husk ash as a supplementary cementing material, J. ACI. Mat., 93(6): 629-636.

Received : July, 08, 2008;

Accepted : December 14, 2008 